\title{
Analysis of the application of fragmented learning in the liberal arts students information literacy training
}

\author{
Xiaoming Huang \\ Nanchang institute of science \& technology, China
}

Keywords: information literacy, micro class, fragmentation, video, liberal arts students

\begin{abstract}
The micro class is fragmented video learning resources, currently the demand of fragmented learning is growing, fragmented video learning resource is one of its indispensable elements. Based on the investigation and analysis of the current situation of the information literacy education for the liberal arts majors in the university, this paper discussed the micro class in the application of liberal arts students information literacy education, put forward how to build project of fragmented video learning resources, and pointed out the applicability of fragmented learning.
\end{abstract}

"Information literacy" is the essence of global information need people to have a kind of basic abilities. It's definition comes from the American Library Association, ALA in 1989, it is about information comprehensive literacy which is a complex of information consciousness, information morality, information knowledge and information skills based on information technology. In the information age, information literacy is an important personal quality, it constituted the foundation of innovating and learning how to learn for the educatees with creative thinking and problem solving skills. Information literacy training is an important part of undergraduate study in the university for liberal arts students.

Person's life, time is the most precious, is called an inch of time is worth an inch of gold. Fragmented time refers to the fragmented and short time. For example, fragmented time is like the leisure time between two things, waiting for a bus or train, queuing, waiting for some people and so on. Many a little make a mickle, the sand accumulates to form a pagoda, the amount of fragmented time is very considerable. Fragmented time has always been there, how to use the fragmented time, vary from person to person. With the coming of information society, the pace of life speeds up, time is more and more fragmented. Social competition intensifies, the requirement of people is more and more high, how to make full use of fragmented time to study, to improve their qualities and competitiveness, has become an increasingly important issue and growing demand.

How to effectively carry out the fragmented learning? First of all, distance education and mobile learning broke through the limitation of time and place, is the best way to go ahead fragmented learning. Secondly, to deal with the fragmentation of learning time, must have the fragmentation of learning resource, so-called, good horse matching good saddle can run very fast and ride far. Three key elements of distance education, mobile learning, fragmented learning resource make the fragmented learning primary and effective. Video learning resource fragmentation can be divided into two ways:

(1)Visualization of the encyclopedia. According to the architecture of knowledge or skills, list the learning point, one learning point shooting a video, do not limit the time, tell people clearly is very good. Because of containing a single content, the corresponding video file playback time should be shorter. This approach is to physically do fragmentation, entry, searchable, at the same time, from the overall view, system of knowledge or skills is systematic.

(2)Logical segmentation of video course. A complete section of the video courses, logically, the division of learning points is used as a unit, for each learning point corresponding playing time, set the access points. Previous learners can retrieve the smallest unit is one lesson, now can retrieve the smallest unit is learning points in this lesson. The learners first to see is a learning point menu, they can watch from beginning to end, can also according to the study points to get, that is logically did fragmentation.

The so-called "micro class" is a miniaturized and fragmented video learning resource. It is 
designed and developed to aim at a discipline knowledge points or teaching link and the length of micro teaching video clips is 5-10 minutes, in addition, it also contains auxiliary teaching and learning resources which corresponded to the learning video content, such as the teaching design, the practice test, teaching reflection and so on. Micro class is a relatively complete education system through inner semantic connection of several micro course content, with characteristics of content essence, modular, contextualized and semi-structured, is suitable for the sharing and spreading of network platform, designed to provide students learning resources with easy to use, easy to get, suitable and practical.

\section{Current situation of liberal arts students information literacy education.}

According to the survey, most of the liberal arts students' information literacy level is low. In the aspect of information consciousness, many students' purpose to use the Internet is not for the professional learning and finding the learning materials, but leisure entertainment, Internet randomness is larger, lack of professional guidance. The desire to share and spread the information is stronger, but less professional information sharing. In the aspect of information skills, more than half of students reflect a little knowledge of professional literature retrieval, the information mastered to use the knowledge more patchy, not systematic enough. Two thirds of the students lack of the demonstrate information in the paper writing, won't be able to use the reference materials and combine their own paper to carry on the extensive reading and the critical thinking deeply. In the aspect of information ethics, non-standard phenomenon is more in the paper writing, for example, misquoted or random changed the contents of the citation, literature reference citation format is not standard, etc. The above problems are mainly divided into two points: one is the information literacy courses not be combined with professional teaching, lack of the communication between teachers and students for professional course; another is the teaching mode is monotonous, the teaching units are long and complicated, network course system is incomplete, learning resources are not abundant. In the professional course teaching should pay attention to train students' information consciousness, information ability, professional literature retrieval ability and information morality level.

\section{The necessity and feasibility of micro class applied to information literacy education for liberal arts students.}

First, the information technology course is suitable for developing into micro class. The practical of information technology course is very strong, but knowledge points are scattered, the independence of teaching content is strong. For example, the contents of the literature retrieval course can be presented by micro class, pass teaching resources to the students, such as the professional journal database, books database, the self-made test and so on. Secondly, colleges and universities have the hardware foundation to implement micro class teaching. The penetration rate tablet PC and mobile terminal is very high, the holding rate of mobile terminal is as high as $100 \%$, in addition, the electronic reading room or network autonomous learning platform also can be used to watch the micro class video for students. Finally, the teachers and students to understand and agree with the micro class is more and more high.

\section{The development of fragmented video learning resources for liberal arts students information literacy}

a.Video learning resource fragmentation can be summarized as two ways. (1) Visual teaching. According to the architecture of knowledge or skills, list the learning point, one learning point shooting a video, do not limit the time, tell people clearly is very good. This approach is to physically do fragmentation, entry, searchable, at the same time, from the overall view, system of knowledge or skills is systematic. (2) Logical segmentation of video course. A complete section of the video courses, logically, the division of learning points is used as a unit, for each learning point 
corresponding playing time, set the access points. The learners first to see is a learning point menu, they can watch from beginning to end, can also according to the study points to get, that is logically did fragmentation.

b.The development of micro class resources. (1) The teaching design. Teaching design is the key to successfully build a micro class, from the characteristics of ontology, the micro class is a kind of video as the carrier, and is the micro course with outstanding theme, short and easy to expand. From the point of view of application, the micro class is the teaching resources which is available for students to take advantage of the fragmented time and personalize the autonomous learning. Then, teaching design behavior will be fully considering these two points which base on micro class, to choose a teaching content with theme prominent and focus clear, and fully mobilize the necessary teaching means and teaching strategies, to form a clear idea of teaching. (2) The micro courseware design. Micro class is the core of the micro video, micro courseware is the important component of the micro video, analyzing the learners' cognitive characteristics, according to the characteristics of discipline, from the perspective of learners, carefully select and organize media, meanwhile can reflect the teacher's leading role. Micro courseware based on a knowledge point (key point, difficult point and doubtful point) to present the related content, therefore, keep every page is simple and clear, each page shows a best information point or a piece of information. According to the teaching process and the course content, reasonably use the navigation menu or clear learning path, to minimize the jump between the pages. Designing a corresponding learning menu, to retrieve the learned content easily. (3) Recording and post-editing. Before recording, requests the teacher to communicate and coordinate well with the photographer, familiar with the teaching process, the photographer to determine differences design, teachers' reasonable allocation of teaching time. Teachers in the teaching need to use the corresponding recording screen software, to record the process of teaching demonstration. About post-editing, first need to completely integrate the video and record the screen content, this part should be repeated, then need consider the opening, until the end, add background music, etc., to beautify the micro class video, in order to achieve good results. (4) The teachers of information technology and various relevant professional need negotiate cooperation, to overall plan for micro class development. In line with the principle of gradual deepening, to divide the course content into several big problems, to integrate every problem of the teaching design, micro video assisted learning information, etc into a complete set of micro teaching and learning system, and to guide students to learn and master course knowledge step by step.

Fragmented study is very suitable for liberal arts students, this is because (1) The learning focus of these students is not here, so no long time to study information technology knowledge, time highly fragmented. (2) These students' understanding ability and self-study ability is strong, there are the basis of autonomous learning. (3) These students are mostly due to the problems encountered in the actual learning to learn, have active learning motivation. (4) The demand for knowledge and skills is different, each need is individualized learning. (5) These students' learning needs once produced, fragmented learning can often play an antidote to against the disease and timely assistance effect.

Throughout one's life, in the age of the students, we not only have to accept formal school education and system learning, more important is to learn how to use the best way to learn, even though we have left school and entered the society, in order to adapt to social progress and the needs for their own development, are acceptable to continue education.

\section{References}

[1]Fuyin Xu. The new technology. New media and new era [R]. Guangzhou: South China Normal University, 2013.

[2]Kee, T. P. The one minute lecture [J]. Education Chemistry, 1995, (32). 
[3]Tiesheng Hu. "Micro class" : the new trend of development for education information resources [J]. E-education research, 2011, (10).

[4]Jiahou Li. The meaning and development of the micro class [J]. Information technology education for primary and secondary schools, 2013, (4).

[5][America] Cher, Israel, Translated by Wenke Ren. Weibo force [M]. Beijing, publishing house of China Renmin University. 2010.

[6]Jun Zheng, Yining Wang, Kailing Wang, Yu Bai. The design research of the micro study video [J]. China audio-visual education, 2012 (4).

[7]Lianfu Li, Liyan Weng. After "micro era" comes [N]. China education news, 2013. 